\title{
A economia da exclusão: Papa Francisco e sua perspectiva sobre o capitalismo
}

\author{
The economy of exclusion: Papa Francisco and its perspective on capitalism \\ La economía de la exclusión: el Papa Francisco y su perspectiva sobre el capitalismo
}

Recebido: 01/03/2021 | Revisado: 09/03/2021 | Aceito: 19/06/2021 | Publicado: 30/06/2021

Francisco Junior De Oliveira Marques
ORCID: https://orcid.org/0000-0002-2684-6499
Universidade de Fortaleza, Brasil
E-mail: sssmarquez@ hotmail.com
José Cândido da Silva Nóbrega
ORCID: https://orcid.org/0000-0002-0976-3763
Universidade Federal de Campina Grande, Brasil
E-mail: jcandidosn@ @ol.com.br
Gina Vidal Marcílio Pompeu
ORCID: https://orcid.org/0000-0003-0446-7452
Universidade de Fortaleza, Brasil
E-mail: ginapompeu@ unifor.br
Francyely dos Santos Moura
ORCID: https://orcid.org/0000-0003-3791-2049
Universidade Federal do Rio Grande do Norte, Brasil
E-mail: mourafrancyely@gmail.com

\section{Resumo}

$\mathrm{O}$ artigo analisa a crítica do Papa Francisco ao capitalismo. O princípio constitucional da solidariedade que une as ordens social e econômica nos Estados democráticos de direito enfrenta dificuldade de aplicação em razão dos limitados recursos financeiros nos Estados. Após a crise de 2007-2008, muitos Estados puseram em marcha um programa de austeridade dos direitos sociais. Paralelemente, setores como os bancos lucraram duas vezes mais do que na década anterior à crise, como foi o caso do JPMorgan (entre 2008-2018 lucrou US\$ 200 bilhões). Esse contexto lançou o capitalismo contemporâneo no limbo da desconfiança, e levou o Papa Francisco a conceituá-lo de "economia da exclusão e da desigualdade". O texto enfoca uma crítica do Pontífice ao capitalismo ideal e real, e propõe sua refundação pautada em valores humanistas. Afinal, qual o capitalismo Francisco se refere e que proposta articular à luz do seu magistério da economia solidaria? A metodologia é interdisciplinar, articula direito e economia, de natureza indutiva-dedutiva, bibliográfica, documental e pesquisa qualitativa. Os resultados obtidos levam a concluir que Francisco não propõe um regime econômico alternativo, mas oferece fundamentos para conciliar o crescimento econômico com o desenvolvimento humano e efetivar os direitos sociais presentes no constitucionalismo do Século XX.

Palavras-chave: Capitalismo; Papa Francisco; Economia da exclusão; Capitalismo humanista.

\begin{abstract}
The article analyzes Pope Francis' critique of capitalism. The constitutional principle of solidarity links the social and economic orders in democratic states governed by the rule of law faces difficulties of application due to the limited financial resources in the states. After the crisis of 2007-2008, many states launched an austerity program for social rights. At the same time, sectors such as banks made twice as much profit as in the decade before the crisis, as was the case with JPMorgan (between 2008 and 2018 it made US\$ 200 billion). This context drove contemporary capitalism into the limits of mistrust, leading Pope Francis to conceptualize it as an "economy of exclusion and inequality". The text focuses on the Pontiff's critique of ideal and real capitalism and proposes its refunding based on humanist values. After all, what does Francis' capitalism refer to and what proposal should it articulate in the light of his magisterium of solidarity economy? The methodology is interdisciplinary, articulates law and economics, inductive-deductive nature, bibliographic, documentary and qualitative research. The results obtained lead us to conclude that Francis does not propose an alternative economic regime but offers foundations to reconcile economic growth with human development and to implement the social rights present in the constitutionalism of the 20th century.
\end{abstract}

Keywords: Capitalism; Pope Francis; Economy of exclusion; Humanist capitalism.

\section{Resumen}

El artículo analiza la crítica del capitalismo del Papa Francisco. El principio constitucional de solidaridad que une los órdenes sociales y económicos en los estados democráticos de derecho enfrenta dificultades de aplicación debido a los limitados recursos financieros de los estados. Después de la crisis de 2007-2008, muchos estados han puesto en marcha un programa de austeridad para los derechos sociales. Al mismo tiempo, sectores como los bancos obtuvieron 
el doble de ganancias que en la década anterior a la crisis, como fue el caso de JPMorgan (entre 2008 y 2018 obtuvo ganancias de \$200 mil millones). Este contexto arrojó al capitalismo contemporáneo al limbo de la desconfianza y llevó al Papa Francisco a conceptualizarlo como una "economía de exclusión y desigualdad”. El texto se centra en la crítica del pontífice al capitalismo ideal y real, y propone su refundación a partir de valores humanistas. Después de todo, ¿cuál es el capitalismo al que se refiere Francisco y qué propuesta articular a la luz de su enseñanza de la economía solidaria? La metodología es interdisciplinar, articulando derecho y economía, de carácter inductivodeductivo, de investigación bibliográfica, documental y cualitativa. Los resultados obtenidos llevan a concluir que Francisco no propone un régimen económico alternativo, pero ofrece bases para conciliar el crecimiento económico con el desarrollo humano y la realización de los derechos sociales presentes en el constitucionalismo del siglo XX.

Palabras clave: Capitalismo; Papa Francisco; Economía de la exclusión; Capitalismo humanista.

\section{Introdução}

Uma década após a queda do muro de Berlin, o comunismo deixou o leste europeu, e consolidou-se a vitória do capitalismo no Ocidente. O fim da história, descrito na obra de Francis Fukuyama, “o fim da história e o último homem” de 1992, apresenta o último estágio do avanço econômico. Não significa o fim da história social ou fim dos acontecimentos naturais como vida ou morte, mas sim, o advento de uma sociedade tecnológica que pudesse suprir todas as necessidades humanas. Ao atingir este estágio, ocorreria o fim do desenvolvimento dos princípios e das instituições básicas, pois todas as questões realmente importantes estariam resolvidas. Para Fukuyama, a vida na democracia liberal e capitalista é o caminho da abundância material e realização da dignidade humana.

Em 09 de novembro de 2019, celebrou-se 30 anos da queda do muro de Berlim, 03 décadas do início da simbólica hegemonia do capitalismo, contudo, ao invés da riqueza universal do mundo democrático e liberal, testemunha-se um crescente mal-estar quanto a ideologia e a realidade capitalista. Nos EEUU, centro do capitalismo mundial, a pesquisa do Gallup 2018 mostrou que é cresce a rejeição ao capitalismo e, consequentemente, o acolhimento ao ideal socialista. Entre os norteamericanos com idade de 18 a 29 anos, 51\% pensam ser o socialismo mais positivo que o capitalismo. Estes números representam $12 \%$ de jovens que desistiram do capitalismo desde 2010, ano da pesquisa anterior. Ainda que na contagem global, o capitalismo seja melhor considerado, a tendência, ano por ano, mostra uma desilusão constante entre os americanos quanto ao capitalismo.

No texto de John Humphrys, intitulado: Capitalism: the Problem or the Solution” de 2018 (yougov.co.uk), encontrase uma crítica contundente de Jeremy Corbin ao capitalismo e, na sua opinião, a necessidade de uma radical transformação socialista do sistema econômico. Mesmo os defensores do capitalismo, como Deirdre McCloskey, preferem usar market-tested inmprovement ou genericamente Bourgeois Civilization que o tradicional conceito de capitalismo.

Todos esses dados mostram que o modelo capitalista hoje gera mal-estar civilizatório e uma crítica a sua ideologia e experiências concretas. Nesse contexto, uma das vozes mais proeminentes atuais, que convida ao reexame do capitalismo, é aquela do Papa Francisco. Sua análise tem diversas perspectivas geoeconômicas (América, Europa, África e Ásia). Francisco critica uma certa forma de capitalismo em diversas oportunidades, seja por discursos, entrevista e livros, identificando-o como a economia de exclusão e da desigualdade. O texto mais articulado com essas críticas é a Exortação Apostólica Evangelii Gaudium, de 24 de novembro de 2014. Assim, escreve Francisco, n. 53 da sua Exortação Apostólica: “Assim como o mandamento 'não matar' põe limite claro para assegurar o valor humano da vida, também hoje devemos dizer não a economia da exclusão e da desigualdade social. Esta economia mata”.

Entretanto, é importante fazer notar que Francisco não faz uma crítica sectária ao capitalismo in genere. Na verdade, o pontífice está na vanguarda de uma nova forma de capitalismo dialógico, capaz integrar desenvolvimento social e economia. Nesse sentido, Francisco convocou o mundo para dialogar sobre uma forma de economia humanizada. Em março de 2020, em torno da juventude inovadora e empreendedora, realizar-se em Assis The economy of Francesco, reunido pensadores como Amartya Sem, Muhammad Yunus, Vanda Shiva, Jeffrey Sachs, Bruno Frey, Kate Raworth, Carlos Petrini, Stefano Zamagni e 
Tony Meloto. Este movimento, por um capitalismo humanizado, já está na terceira edição com o Impact investing Conference em Roma (2014, 2016 e 2018)

Ao considerar um movimento crescente, opondo-se ao capitalismo laissez faire e sua forma de propor desenvolvimento humano em base ética, especialmente, sintetizada pela voz do Papa Francisco, nasce a pergunta do presente artigo: qual o capitalismo Francisco se refere e que proposta articular à luz do seu magistério da solidariedade econômica?

Nesse sentido, o percurso da pesquisa iniciará com uma abordagem ao capitalismo ideal e real, com o objetivo de conceituá-lo e apresentar alguns de seus importantes teóricos. No item seguinte, será apresentado as bases do pensamento social e econômico da Igreja Católica, especialmente, à luz do pensamento tomasiano, e suas semelhanças e diferenças com o modelo capitalista liberal. Finalmente, na esteira dessa tradição eclesial, no magistério de Francisco, apresenta-se uns topos crível na tarefa de analisar e criticar uma espécie de capitalismos que separa economia e desenvolvimento social, exigido do Estado democrático de direito constitucional uma via de reconciliação.

\section{O Capitalismo Ideal e Real: a Opção pela Ideologia do Mercado}

O motor propulsor do capitalismo é a acumulação de riqueza, o processo pelo qual o dinheiro torna-se mais dinheiro. Tudo o mais está subordinado a esse propósito, e se as expectativas lideradas por esse processo se frustram, o resultado é a crise econômica. O desejo por mais e mais riqueza é antigo, contudo, o que faz do capitalismo diferente é a reorientação da vida social, política e religião à subordinação a esse objetivo.

A fundação filosófica do capitalismo é o homo economicus como homem racional econômico. Aqui, o homem é um ator autônomo-econômico guiado pelo interesse próprio e perseguindo a utilidade do mundo. Adam Smith, pai das ciências econômicas, leciona que a economia, entendida à luz da teoria do mercado, é o postulado científico para a ordem liberal. No mercado, os interesses privados ao invés de se chocarem produzem bem-estar social, e geram uma moral smithiana baseada na empatia social e no autocontrole, transmudando ganância em prudência. A lógica do mercado liberal, agraciada por uma "mão invisível", orienta a todos ao bem-estar coletivo.

Essa lógica encontra raízes em Montesquieu, um dos topos originais do pensamento liberal. Na sua obra De l'esprit des lois (1748) tem-se uma das melhores sistematizações da ideia da "mão invisível', associada a uma forma embrionária do mercado (comércio internacional entre as nações). Na teoria do doux commerce, Montesquieu leciona que o comércio suaviza os costumes e promove a paz entre as nações.

Smith, em suas obras, Teoria do Sentimentos Morais (1759) e a Riqueza das Nações (1776) retoma o conceito de amor presente na simpatia. $\mathrm{O}$ amor próprio é construído pela admiração, reconhecimento e aprovação como conjunto de virtude que leva a prudência, especialmente, porque sua antropologia, destaca o homem magnânimo, cuidador da família, merecedor de aplausos. O homem prudente da riqueza é o homem adequado, capaz de melhorar sua própria condição mediante a potencialização dos seus interesses privados, que por sua vez, não são selvagens e tampouco identificação com o movimento self interest neoclassista.

Na Escola neoclássica do liberalismo, com pensadores como Francis Edgeworth, Ludwig von Mises, August von Hayek, Ayn Rand e Milton Friedman, o ponto central é o que se denomina de sociedade livre, fundada nas liberdades individuais e que permite que cada um seja livre para perseguir seus próprios interesses no materialismo econômico. Consoante Mises (1987), a única restrição a esta liberdade é que o direito não seja cerceado por outro. Seguindo o liberalismo smithiano quanto ao aspecto fundamental do individualismo, a escola neoclássica distancia-se de Smith ao desfazer-se da sua antropologia e moral. O novo liberalismo não trata da felicidade ou das aspirações nobres do homem, mas tão somente de satisfazer todos os desejos materiais. 
Francis Edgeworth, economista britânico do fim do séc. XIX, em seu livro Mathematical Psichics, explica que o primeiro princípio da economia é que todo agente atue sozinho em razão do seu interesse próprio, e que o funcionamento desse princípio se dar sob o duplo aspecto da guerra e do contrato. Nas relações mercantilistas, conforme Edgeworth (1881), a relação é preponderante de guerra e contrato entre os indivíduos.

Além da autonomia e individualismo, outro ideal capitalista central é a propriedade privada. Na filosofia política moderna de John Locke, o capitalismo encontra sua fundamentação ética no conceito de propriedade. O argumento de Locke, segundo seu Second Treatise on Government, é que a pessoa pode ser proprietária (por direito natural) quando combina seu trabalho (próprio da pessoa) com a matéria natural (aquilo que a ninguém pertence). Portanto, diz Locke, quando alguém colhe uma maçã da árvore, aquela não pertence a ninguém, e assim, é moralmente propriedade dessa pessoa, e apenas dela.

Na sua elaboração, Locke aplica algumas restrições à propriedade. O indivíduo pode ter o quanto poder e desejar de maças contanto que não permaneça com elas até que estrague, e impeça ou exclua que outro possa tê-las, sendo uma espécie de limite a acumulação de bens. Para superar esse limite, Locke ensina: 1. Se a pessoa converte o que tomou da natureza em dinheiro, então pode acumular sem limites. 2. A produção do trabalho de seu empregado ou escravo é algo que também pode ser acumulada sem limites. Em Locke tem-se a base da "Teoria do Valor do Trabalho" usada por Adam Smith e Karl Marx para explicar relative prices e, ao mesmo tempo, a justificação moral da acumulação ilimitada.

Importante notar que o capítulo sobre propriedade lockiana segue ao capítulo sobre escravidão, que aparentemente Locke abominava como uma violação da lei da natureza. Entretanto, Locke fornece uma exceção, nos casos dos escravos que são capturados na guerra, aplicado neste raciocínio para justificar escravos africanos nas colônias inglesas (ele de fato era um investidor no comércio de escravos).

Consoante Telly (2013), Smith defende a propriedade em base a Locke (ideia seminal da liberdade), contudo a noção fundamental para Smith ligada a propriedade privada é a eficiência. Uma propriedade é usada com maior eficiência se cada proprietário individualmente direciona seu uso para os interesses do próprio proprietário. Esse argumento quer afastar a interferência do governo e ao mesmo tempo reforçar o controlo individual. Segundo Smith (2007), a "mão invisível" do mercado, ou seja, a competição, garante que os recursos serão usados onde mais benefícios trouxer (o que, naturalmente, significa onde eles irão render o maior retorno).

A abordagem marxista define capitalismo a partir dos "modos de produção". Capitalismo é um "arranjo social de produção", e um conjunto de instituições que tipificam a economia capitalista são: propriedade privada dos meios de produção, governo mínimo para regulação da economia, mercado determinado pelos preços e tomada de decisões económicas individuais. Consoante Heilbroner (1985), Max Weber, por sua vez, define capitalismo a partir da "mentalidade racional burguesa", tendo o empreendedorismo como única realidade do capitalismo.

Dos ideais filosóficos-epistemológicos do capitalismo produziu-se um capitalismo real aplicado nos Estados ocidentais. No seu ensaio Bourgeois Ideal and Capitalis Reality, Werner Stark (2014), faz notar que são os ideais burgueses (individualismo e materialismo) que formam a moral fundamental e justifica o livre mercado capitalista, de uma sociedade livres do controle social do governo e instituições religiosas. Os resultados produziram um equilíbrio de prosperidade e igualdade (e não o caos).

De fato, o ideal capitalista usa o mecanicismo clássico newtoniana para argumentar que a economia de mercado livre está organizada em base ao sistema de equilíbrio, que os egos individuais atomísticos, no contexto da competição de mercado, serão liderados pelo que Adam Smith chama de "mão invisível" para produzir o melhor da prosperidade e estabilidade. Como declara Stark: ao estabelecer um equilíbrio de forças, os filósofos burgueses pensavam que poderiam liberar os indivíduos de todas as restrições.

De acordo com Mccloskey (2018), O uso do conceito de equilíbrio como ideia organizadora central para compreender 
o capitalismo desafia a experiência da história conhecida pelas economias capitalistas reais. O conceito de Schumpeter de “destruição criativa” é mais bem aplicada (uma agenda política mais difícil de vender). Nesse sentido, os ideais burgueses comprometidas mediante o equilíbrio newtoniano da equidade e eficiência, ao invés da abundância universal, criou uma história de autoproteção, autodefesa e medo em razão das mudanças.

Medo de mudança é uma das características do ser humano. Ainda que a história mostre que a mudança pode significar progresso e melhoria, sempre haverá resistência. Além do mais, os benefícios da mudança geralmente chegam para aqueles que os promove e, os custos, por sua vez, caem noutro lugar. Para Polanyi (1957) no caso da revolução mercantilista liberal, os benefícios abundaram para os mais ricos, enquanto gotejaram para os mais pobres. A exigência foi liberar a terra, o trabalho e o capital dos seus laços sociais. Em outras palavras, os trabalhadores deveriam ser liberados dos seus direitos, de seus meios de subsistência tradicionais, de suas obrigações sociais, e obrigados a vender seu trabalho por um salário, competindo, com outros trabalhadores livres. De fato, passaram-se duas ou três gerações da revolução industrial quando os salários reais começaram a subir, contudo o retorno do capital foi imediato.

O sonho Smithiano do equilíbrio foi persuasivo para os economistas modernos, contudo nenhum país planejou sua economia futura na dinâmica da "mão invisível” do mercado. O capitalismo laissez-faire neoclássico jamais foi implementado, ou mesmo o capitalismo neoliberal contemporâneo, em sua amplitude ideológica. Neste último caso, basta observar as projeções dos países capitalistas neoliberais na ampliação de políticas econômicas em base ao welfare state.

Ainda que a crise mundial tenha sido persistente, Célia Kerstenetzky e Graciele Guedes (2018), ao tomar como base uma pesquisa com os países membros da $\mathrm{OCDE}^{1}$, afirmam que o welfare state resiste. Para estes pesquisadores, as profecias de encolhimento do Estado de bem-estar social não se confirmaram. Ao contrário, o Estado social não encolheu, mas dilatou-se; aumentou sua capacidade de distribuição, e o mundo chamado desenvolvido, ainda sustenta um Estado social que impede a desigualdade fratricida de uma espécie de capitalismo laissez-faire. A proporção de gastos sociais seguiu crescendo no bloco da OCDE, mesmo quando o PIB não crescia, ou mesmo contraía, como foi o caso dos anos 2008 e 2009, evidenciou-se maior esforço do Estado social em tempo de recessão. Nos anos seguintes de 2008-2009, com o crescimento do PIB, restabeleceu-se o investimento em patamares mais elevados, e o ano de 2016 chegou-se a média superior de $21 \%$ do PIB.

Os homens práticos, geralmente, não seguiram os moldes liberais puros, ao menos até que o país tenha chegado ao mais alto estágio de desenvolvimento. A ideologia do mercado livre capitalista, tornou-se, como indica um economista de Cambrigde, Hajoon Chang, um caminho de kicking away the ladder (2002), a religião do laissez-faire, que clama: "Senhor dáme o comércio livre, mais não agora". ${ }^{2}$

Quase todos os países que se tornaram avançados na economia capitalista, o fizeram mediante políticas intervencionistas e evitando aplicação irrestrita de Adam Smith e seus posteriores. Além disso, os que desenvolveram uma forte classe média apenas o fizeram com políticas de proteção aos trabalhadores (como de apoio aos sindicatos) e apoio às famílias.

A história da política econômica dos EEUU é um exemplo da tendência global. Depois de algum tempo da independência, Alexander Hamilton recebeu como encargo lançar as bases para a construção da nova nação. Hamilton estudou “A riquezas das Nações” de Adam Smith, contudo rejeitou suas políticas do capitalista de livre comercio, defendo políticas de taxação para proteger a indústria nacional. Thomas Jefferson e os proprietários do Sul se colocaram contra a política de Hamilton em razão do intervencionismo estatal pela tarifação das riquezas, especialmente, a riqueza dos proprietários de

\footnotetext{
${ }^{1}$ Organização para a Cooperação e Desenvolvimento Econômico (OCDE), conhecida como "clube dos ricos", tem atualmente 36 membros, dos quais México, Chile e Turquia apresentam o mesmo nível de desenvolvimento econômico ao do Brasil.

${ }^{2}$ Parafraseando Agostinho, "Dá-me a castidade e a continência, mas que não seja para já". (Santo Agostinho. (2016). As Confissões. Col. Patrística. $7^{\text {a }}$. Ed. São Paulo: Paulus, p. 135).
} 
escravos. Ninguém duvidaria que o capitalismo smithiano promoveu uma moral e economia ligada aos direitos humanos, a liberdade, vida e felicidade. Contudo, o capitalismo laissez faire levou ao paradoxo das ideias humanistas e a eficiência do mercado a uma resposta evidente: é preciso ficar com o mercado. Aqui ver-se claramente o descompasso entre moral e capitalismo real.

Exemplo notório dessa escolha pela eficiência descolada da moral é a cultura da especulação. No relatório dos bancos que mais lucraram na década após a crise de 2008, JPMorgan acumulou U\$ 200 bilhões de dólares, o dobro da década anterior. ${ }^{3}$ A crise, portanto, se confirma na primeira referência a natureza do capitalismo feita acima. $\mathrm{O}$ dinheiro deve-se tornar dinheiro e não importa a relação indivíduo e comunidade, mas apenas a liberdade de acumular.

\section{Repensando Conceitos Capitalistas com Santo Tomas e a Tradição da Igreja}

O ensinamento da Igreja Católica sobre questões económicas, não é uma prática estranha ao conjunto do seu magistério. Neste sentido, observa-se uma tradição cultural e intelectual de reflexão sobre temas sociais e econômicos que formar o Ocidente, especialmente, após a Revolução industrial, quando a Igreja se viu exigida a engajar-se em tais temas. Quanto ao capitalismo, desde o início, o magistério eclesial foi crítico a sua ideologia, particularmente, ao capitalismo laissezfaire. Sua crítica postou-se na glorificação e institucionalização da ganância, e no abismo entre economia e valores morais como foi descrito no item anterior.

O papa Leão XXII iniciou este magistério com a Encíclica Rerum Novarum, sobre as condições de trabalho, em 1891. Com esse texto, a Igreja dá inicia ao chamado "Pensamento Social Católico" como forma de dialogar com as realidades socioeconômicas estabelecidas pelo capitalismo dos XIX e XX. Esta tradição reage aos novos desafios criados pela Revolução Industrial, especialmente, as condições desumanas dos trabalhadores e pobres dessa época, bem como, a ideologia capitalista que, de diversas formas, contrata com os valores cristãos.

O cristianismo sempre viu a ganância como um vício, e não como uma virtude. De fato, a ganância e os juros desmedidos eram condenados pelas tradições religiosas, e o controle daqueles sempre passaram pelas instituições civis e religiosas. Tal controle por parte ensinamento da Igreja Católica não se realiza por uma proposta de sistema econômico alternativo.

O gap que separa os ideias e realidades vividas do Cristianismo e capitalismo, apenas reafirma a função profética do Cristianismo de levantar questões e fazer pontes para respostas melhores diante dos desafios humanos. A Igreja tem a função de humanizar os sistemas sociais, e não pretende estabelecer uma economia teocrática. Nesse sentido, eleva sua voz para oporse a todo individualismo, juros desmedidos, acumulação de riqueza e consumismo.

Na perspectiva cristã, o homem é indivíduo e comunidade, persona e trinitas. Para Jacques Maritain, o homem é uma pessoa e não um indivíduo, e o postulado de criticidade da pessoa humana é a sua natureza social. Assim, o homem não pode ser humanidade sem alteridade, ou solidão. A crítica à antropológica belicosa e contratualista de uma certa forma de capitalismo que aponta para uma outra forma de pensar o ser humano está arraigado na racionalidade e cooperação.

Contudo, não é só com o ideal individualista que o magistério eclesial contrata com o capitalismo laissez-faire. A propriedade é outro conceito fundante que passa pelo crivo da crítica humanista. Na verdade, a neoclássica liberal herdou parte do conceito tomista e reelaborou na sua perspectiva individualista.

O entendimento sobre propriedade cristão segue a perspectiva aristotélico-tomista. Tomás de Aquino define a relação entre os homens e as coisas exteriores pela posse própria e comum. O dominium sobre as coisas não está reduzido à propriedade, e engloba a jurisdição sobre as coisas, a posse comum e o direito ao uso (usus).

${ }^{3}$ Ver fintechs.com.br/relatorio-os-bancos-que-mais-lucraram-na-decada-apos-a-crise-de-2008. 
O tema da propriedade não é um tema abordado em si mesmo, mas mediante o estudo da justiça, em razão da necessidade da restituição (IIa-IIIae, q. 62) e, sobretudo, quanto a questão do roubo (IIa-IIIae, q. 66). Tomás define restituição como o fato de reestabelecer a alguém "na posse e no dominium de seu bem." (in possessionem vel dominium rei suae, IIa-IIae, q. 62 , a.1). Ele propõe uma equivalência entre dominium e posse. Para entender melhor quanto ao tema é necessário tratar a questão 66 da Suma Teológica, consagrada ao tema do roubo, considerado uma violação à justiça pelo prejuízo que se produz a outrem.

Tomás examina metodicamente as relações entre os homens e as coisas exteriores e precisa em que sentido pode-se possuir. A certo momento, propõe duas questões ( IIa-IIae, q. 66, a.1 e a. 2): a posse das coisas exteriores é natural ao homem? É permitido as pessoas possuírem uma coisa como própria (quasi propriam)? A primeira trata da posse das coisas exteriores em geral, enquanto a segunda, trata da propriedade no sentido estrito.

Tomás inicialmente distingue na coisa, sua natureza e seu uso. Ele afirma que a natureza das coisas não está submetida ao poder do homem (humana potesta), mas somente a Deus. O homem não tem poder sobre a natureza das coisas, mas tem o poder natural (naturale dominium) sobre as coisas quanto ao seu uso, pois, pela sua razão e sua vontade, ele pode utilizar como sendo para ele. Como Aristóteles (Política, L, I, cap. 3), Tomás deduz que "a titularidade das coisas exteriores é natural aos homens". Ele identifica dominium sobre as coisas com a sua posse, como já o tinha feito no art. 1, q. 62. Ele acrescenta este dominium natural sobre as coisas em virtude de sua razão (imago Deo). A posse das coisas é vontade de Deus que criou o homem a sua imagem para que este cuide das mesmas. Assim, o homem não tem o poder sobre a natureza das coisas, pois ele não é Deus, mas tem o dominium natural sobre elas.

Até aqui, seguindo a Tomás, não se trata de propriedade ou posse própria. É no art. 2, q. 62 que ele pregunta se se pode possuir coisa própria, ou seja, ter a propriedade. Esta é a questão da propriedade em sentido estrito. Sobre esse ponto, Tomás apresenta uma resposta complexa e mesmo desconcertante (Clark, 2017), pois faz uma distinção entre a administração dos bens e o seu uso.

$\mathrm{Na}$ administração dos bens, ou seja, no poder de produzir, de gerar e fornecer (potesta procurandi et dispensandi), Tomás fala da permissão de possuir as coisas como próprias (possidere propria) e de ter a propriedade. Para Tomás, ter a propriedade é necessária à vida humana por três razões. 1. As pessoas preferem realizar suas próprias atividades individuais que aquelas de todos, pois há uma tendência a deixar o trabalho comum para os outros. 2. As coisas humanas são mais bem tratadas se cada um tem sua tarefa própria (cura propria). 3. A paz entre os homens é mais bem conservada se cada um se contentar com aquilo que tem, sem se preocupar com as disputas entre as coisas comuns. Neste sentido, Tomás afirma a legitimidade e mesmo a necessidade da propriedade das coisas próprias para assegurar a boa administração. Em toda lógica tomasiana do possidere própria tem-se uma teoria prática moderna avant-letre da propriedade privada.

No caso do uso das coisas como dominium, Tomás não admite a propriedade como própria, mas somente como posse comum. Quando trata do uso, o homem não pode ter as coisas como própria, mas somente como coisas comuns ("Non debet homo habere res exterioras ut proprias, sed ut communes"). A razão é que as coisas têm uma destinação comum e que se deve ofertar facilmente aos outros quando da sua necessidade (1Tm 6, 17-18).

A posição tomasiana quanto a propriedade das coisas é a sua vez matizada e clara. Por um lado, admite posse própria ou propriedade privada, justificada pela boa ou melhor administração daqueles que possuem com para si. Por outra parte, a propriedade é comum quando se trata do seu uso, sempre disponível a satisfazer a necessidade daqueles mais necessitados. Ademais faz duas precisões, ao tratar da relação entre propriedade e direito natural. Em primeiro lugar, Tomás recorda que em direito natural, todas as coisas são comuns, contudo, isso não quer dizer que tudo deve ser possuído em comum e nada como coisa própria. O Tomás deixa claro que a possibilidade da propriedade não decorre do direito natural, mas da convenção humana (humanum condictum), do direito positivo (Grotius, pactum). A posse dos bens (proprietas pesssionum) não se opõe 
ao direito natural, mas é adicionado à lei natural por uma intervenção da razão humana. Em outras palavras, se o homem tem o dominium natural sobre as coisas, a propriedade não é direito natural (como dirá a Declaração 1789 no artigo 2), mas também não é contrário ao direito natural, podendo ser estabelecida pela razão humana. Note-se, portanto, que para Tomás o direito à propriedade repousa na convenção humana e não vem do poder político do soberano (como pensa Hobbes no Leviatã).

Outra precisão entre propriedade e poder natural visa limitar a propriedade em nome do direito natural. A propriedade das coisas que nasce do direito positivo não impede a sua utilização para providenciar aos mais necessitados (hominis necessitas). O supérfluo dos ricos é devido aos pobres e deve ser doado aos mesmos (Res quas aliqui superabundanter habent, ex naturali jure debentur pauperum sustentationi). A este respeito, Tomás cita o Decreto de Graciano: “O que tens pertence aos que tem fome”. O texto preconiza uma justa repartição de bens de consumo em virtude do direito natural, conforme sua posição quanto a posse comum e ao seu uso que conduz aos limites sensíveis da propriedade privada.

Tomás não apela ao poder político para realizar esta repartição como o fizeram João de Paris, Francisco de Vitoria e Hobbes. Ao contrário, se remete ao julgamento de cada um para socorrer aos necessitados, pois confia-se na razão humana informada pela luz do evangelho (Committitur arbitrio uniuscujusque dispensatio propriarum rerum, ut ex eis subveniat necessitatem patientibus). Para Tomás, todas as coisas são comuns em caso de necessidade ("in necessitate sunt omnia communia », Sed contra", art. 7) e pertence aos necessitados. Essa posição será constantemente retomada, (inclusive em Grotius), mas totalmente esquecida quando a propriedade individual foi considerada direito natural e inviolável (Declaração de 1789, a. 2 e 17). Mas tarde, Marx retomará esta posição tomaisana e afirmará no artigo de 1842 que a "classe pobre" tem um "instinto de direito" ou um "sentido instintivo de justiça".

A análise precedente conduz a algumas conclusões. Tomás de Aquino faz um uso frequente da palavra dominium e, a esta, dá dois sentidos principais. Este termo designa poder sobre as pessoas, sinônimo de potesta ou político-estatal e doméstico; e, designa poder sobre as coisas, ou seja, propriedade. A mesma palavra tem dois sentidos diversos, distinguindo dominium-poder e dominium-proriedade. Tomás não estabelece uma relação entre os dois sentidos de dominium e, por isso, não é o poder político que gera e funda o direito à propriedade como o dirá Hobbes, onde a propriedade é "obra do poder" (Hobbes, \& Zarka). Inversamente não é a propriedade de bens que gera e determina o poder político, como pensará Marx, pela qual as classes possuem os meios de produção e detém o poder político. Nesse sentido, Tomás não tem uma posição muito distante de Rousseau que considera, em virtude do contrato social, que os bens de cada indivíduo são objeto de uma "propriedade pública", pois o Estado, como os seus membro, são possuidores de todos os bens pelo contrato social, e possuidores no sentido de "depositários dos bens públicos".

Tomás não hesita em dizer que o homem tem um dominium natural sobre as coisas e que é natural ao homem possuir. Da mesma forma admite sem dificuldade a propriedade comum das coisas, e justifica a propriedade das coisas somente pela necessidade da boa administração. Essa reticencia frente a propriedade individual é lógica para Tomás, diferente de Locke que justifica a propriedade pessoal e natural. Para este, a propriedade dos bens se funda no indivíduo que tem o direito ou dominium sobre as pessoas, suas ações e seus trabalhos. A propriedade no pensamento moderno implica o direito de uso e disposição das coisas, independente da comunidade. Marx vai traduzir esse uso irrestrito da propriedade privada na independência total daquela à comunidade (Marx, \& Engels, 1998).

Portanto, o pensamento social e econômico da Igreja Católica sustenha-se na filosofia tomasiana, garantindo a propriedade privada, e a melhor administração dos bens por usos próprios, mas também, a necessidade desse uso próprio ser pensado à luz do bem comum. Aqui a Igreja preserva algo de liberalismo, ao ensinar como Smith e seus filósofos da economia moderna precedente, a melhor administração pelo individuo, contudo, amplia seu ensinamento em bases éticos-morais, o que falta, sobretudo, ao liberalismo neoclássico e o neoliberalismo contemporâneo. 


\section{Humanismo Econômico de Francisco Fundado na Tradição e como Superação da Economia de Exclusão}

Nos anos 200 d.C, Clemente de Alexandria, apresentava esta questão: qual homem rico pode ser salvo? Este questionamento, nascido da narrativa dos Evangelhos (Mt 19, 23), impactou de forma desafiadora as comunidades do cristianismo primitivo. Clemente reconhece, segundo a Tradição, que tudo é bom e que os produtos são para enriquecer o homem, satisfazer suas necessites e promover a comunhão. Tomás de Aquino dá continuidade ao pensamento da Igreja Primitiva e avança. Com sofisticada teoria, Tomás elabora um sistema de pensamento científico para fazer dialogar com a capacidade do homem de possuir de forma própria e de fruir de forma comunitária. Esta é a base do pensamento social e econômico da Igreja, assumido e proclamado no pontificado de Francisco.

O Papa Francisco ver a economia em perspectiva da fé e da herança intelectual do ocidente cristão, especialmente, expressada na exortação apostólica Evangelii gaudium (EG) e na encíclica Laudato si (LS). É importante mais uma vez recordar que o magistério econômico de Francisco oferece uma leitura do homo economicus desde o topo religioso, antropológico e ético-moral. Nesse sentido, entende-se a crítica de Francisco a uma forma de sistema econômico de exclusão e iniquidade $(E G, \mathrm{n}$. 53). Pelo crivo do Evangelho, uma certa forma de capitalismo contemporâneo parece muitas vezes prescindir da pessoa humana. Nos termos de Francisco, "já não é o homem, mas o dinheiro que está ao centro. Os homens e as mulheres não são pessoas, mas instrumentos de uma lógica do descartável que gera profundo desequilíbrio" (Tornielli, 2015, p.206).

Pensadores como Avelãs Nunes, Gilberto Bercovici e Noam Chomsky fazem uma crítica ainda mais contundente ao capitalismo laissez faire. Em seu artigo, Política econômica e direito econômico, Bercovici (2011) observa que o estado neoliberal, guiado pelo direito econômico, estabelece um chamado "estado de exceção econômico", onde o poder e autoridade proeminente não é a soberania de um povo e as suas necessidades, mas os mecanismos econômicos que guiam o futuro de uma nação. Avalãs Nunes (2008) em As duas mascaras do Estado capitalista faz uma séria crítica ao poder tecnocrático e pseudoneutro dos Estados capitalistas. Para o autor, a política democraticamente constituída não pode ser substituída pela "mão invisível" do mercado, que na verdade nada tem de invisível, mas representa os aglomerados internacionais (Nunes, 2011). Finalmente, é significativo a expressão de Noam Chomsky, quando declara na revista norte-americana, The Nation, "o neoliberalismo está destruindo nossa democracia". ${ }^{4}$

Francisco se posiciona em uma perspectiva, mas conciliadora, e sua crítica quer fazer notar a separação imposta entre economia e ética da alteridade. Tema caro aos escolásticos e mesmo a Adam Smith, superado pelo movimento neoclássico e contemporâneo do liberalismo. Tal separação conduz ao centro da crise econômica que, em efeito domino, gerou falências, desigualdade, pobreza e outras consequências. A economia de exclusão dará espaço a economia de inclusão e amiga, na medida que a sociedade afrontar uma crise mais profunda, ou seja, a crise antropológica, pois uma "economia sem rosto e sem objetivo humana" ( $E G$, n. 55) é uma economia da desigualdade.

A exigência de represtinar o sentido antropológico e ético da economia diz respeito a urgência de problematizar o atual primado da economia. Nesse primado, como já refletido acima, com a ajuda do Estado democrático de direito, reafirmase a liberação do mercado e a unificação dos bancos comerciais com aqueles especulativos, absolutizando a autonomia em relação a todo o resto e relegando a segundo plano a tradição do constitucionalismo social do século XX. Diante desse reducionismo técnico, é necessário perguntar-se pela responsabilidade ética e social da economia, e de todos os mecanismos automáticos.

A desconstrução semântica exigirá uma resemantização, para fundar a economia e as finanças numa antropologia e

${ }^{4}$ Noam Chomsky em entrevista com Christopher Lydon (The Nation, Jun. 2, 017. Acesso em: www.thenation.com.) 
moral de cooperação. Nesse sentido, deixa claro a Gaudium et Spes, n. 63, o personalismo econômico considera o homem autor, centro e fim de toda a vida econômico-social. Bento XVI, em sua Enciclica Caritas in Veritates (CV), recorda que a economia precisa de uma ética para o seu correto financiamento, mas não uma ética qualquer, e sim, uma ética amiga da pessoa.

Francisco se aproxima de pensados com Mohammand Yunus e Amartya Sen. Yunus na sua obra, Um mundo sem pobreza, faz uma aposta num tipo de capitalismo centrado na necessidade dos mais necessitados. Para ele, o microcrédito não tem como primeiro objetivo a criação de mais empregos, mas o de forma uma cultura de empreendedorismo. O futuro do capitalismo segue a perspectiva de Amartya Sen, que em seu livro, Desigualdade reexaminada, relaciona conceito de igualdade com o de capacidades. Capacidade expressa uma ideia de igualdade de oportunidades, valorizando a liberdade substantiva das pessoas para levarem a vida do jeito que quiserem e de lutarem pelo alcance dos seus objectivos. Para Sen (2008), a desigualdade e a pobreza será superada na medida que esta possa ser mesurada em vista de politicas publicas consistentes.

A atividade ecônomo-financeira tem uma relação intrínseca com a ética, e este ponto de partido, deixa o individualismo, e assume o paradigma da pessoa humana, em termos da liberdade e reponsabilidade, fraternidade e solidariedade, aberto a transcendência. De fato, a Caritas in Veritates atualizou o "ideal histórico e concreto", representado pela economia social, que reafirma a necessidade do contrato e das leis justas para a realização da redistribuição guiada pela política.

Sendo expressão do ser humano fraterno e solidário, a econômica pode ser estruturada e institucionalizada eticamente. Segundo Bento XVI, o ideal histórico-concreto da economia de mercado, funcional ao bem da nação e do mundo, é substancialmente empreendimento plural (profit) e uma área intermediaria (non-profit). Esta última é constituída de empresas de economia de comunhão. Não se trata apenas de terceiro setor, mas de nova e ampla realidade que envolve o privado e o público e que não excluo o profit, mas o considera como instrumento para realizar a finalidade humana e social (VC, n. 46).

Papa Francisco, à luz da visão personalista da economia, questiona o atual fetichismo do dinheiro e a sacralização dos mecanismos do sistema econômico que rejeita a ética e leva a sociedade ao imperialismo econômico, o leviatã incontestável, onde faltam instrumentos legislativos e instituições políticas que o conteste. Segundo o pontífice, o século XXI tem uma governance superada e inadequada aos problemas atuais ( $L S$, n. 175). Ainda que Pio IX na quadragésimo anno (1931) já houvesse falado do imperialismo internacional do dinheiro, com a coragem da sua época, hoje a Evangelium Gaudium reafirma com a fala da economia da exclusão e iniquidade.

Michele Carducci (2014), no seu artigo, il quadrilátero dello sveluppo pergunta-se se é possível o nexo entre desenvolvimento sustentável, humano e constitucional. Como Francisco, Carducci elabora uma crítica à uma espécie de capitalismo ou economia desconectada do Estado e da sua Constituição. De fato, não se trata de uma crise de regulação do mercado financeiro, mas a passagem traumática do processo de desconstitucionalização da relação entre economia e ganhos sociais.

Nos termos de Gilberto Bercovici (2006), trata-se do estabelecimento de um novo nomos planetário. O mercado assume lugar de soberano e se impõe como estado de exceção schmittiano. De fato, a razão do mercado passa a ser a nova racionalidade do Estado, limitando os direitos coletivos em prol das individualidades em base à propriedade privada e a acumulação capitalista.

Importante deixar claro que Francisco não propõe como via ou método marxista. A prática da luta de classes para alcançar a justiça. Esta perspectiva emerge do seu Discorso ai participante all incontro mundiale dei movimenti popolari (28 outubro 2014), que fala da urgência de reforma ao atual sistema econômico em vista de uma economia e uma democracia inclusiva. O Pontífice recorda que se deve mudar e recolocar a dignidade humana ao centro e sobre esta pilastra construir a 
estrutura social alternativa da qual temos necessidade. Esta prospetiva será feita com coragem e inteligência. Com tenacidade, mas sem fanatismo. Com paixão, mas sem violência. E todos juntos, afrontaremos os conflitos sem permanecermos polarizados, buscando sempre resolver as tensões para chegar a um nível superior de unidade, de paz e de justiça.

Nesse sentido, Francisco jamais afirmou que o mercado é um princípio econômico per se injusto. Não há uma condenação a economia de mercado e ao mercado em si. Trazendo a colação a reflexão acima tomasiana, Francisco se insere na mesma teoria econômica da necessidade da defesa da propriedade privada, da individualidade, mas concomitantemente, da liberação do individualismo pela teoria do uso. Sua crítica, portanto, é contra um mercado que se torna religião imanentista, um novo "bezerro de oro". Francisco critica um capitalismo financeiro que prega o livre mercado ao serviço do profit a curto prazo, que gera desigualdade e reduz a liberdade substancial das pessoas, e induz os sistemas democráticos a apresentar a corda para enforcar os direitos sociais e econômicos dos cidadãos (Shiller, 2012). Essa é a face do capitalismo financeiro que absolutiza a especulação sem limites e que é sujeito de crises recorrentes, e antagoniza a liberdade frente a igualdade. Não obstante seja importante um Estado democrático de direito que preserve a liberdade e se abstenha do controle, não significa mutatis mutandis que esse mesmo Estado esteja impedido de intervir para regular e preservar garantias sociais (Pompeu, \& Natercia, 2014).

O Pontífice critica ainda a teoria da economia do gotejamemento (trickle-down, trickle-dow). Como observou Stefano Zamagini, qualquer teoria da economia atual tem claro que a celebrada "curva de Kuznets" não pode ser mais válida. Francisco demonstra entender o que muitos observadores e estudiosos fingem não ver, ou seja, que a pobreza absoluta e a desigualdade demarcadas pela riqueza de um país são fenômenos substancialmente diferentes. A esta equação, pode-se apresentar o exemplo

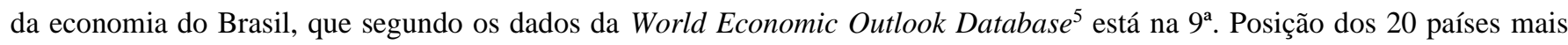
ricos do mundo. Paradoxalmente, o índice do PNUD de desenvolvimento humano coloca a mesma economia na $79^{\mathrm{a}} .{ }^{6}$, abaixo

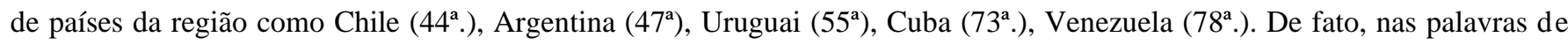
Martha Nussbaum, "produzir crescimento econômico não significa produzir democracia" 0 , ou ainda desenvolvimento humano.

Francisco propõe a superação das atuais doutrinas econômicas neoliberais puras e lança, sobre a base de antropologia e ética, uma economia inclusiva, tendo em conta resultados recentes secundo os quais, a curva de Kuznets não funciona. Num crescimento da economia, favorecida o livre mercado, não corresponde sempre uma maior equidades e inclusão social. É necessário abandonar a confiança ingênua na bondade de quem detém o poder econômico e os mecanismos do sistema. O crescimento da equidade exige mais que crescimento econômico. Exige uma sociedade civil atuante e um Estado com suas intuições democráticas de direito decidindo e construindo mecanismos e processos específicos de orientação em vista de uma melhor redistribuição, para além do assistencialismo.

O pontífice se opõe a sustentadores da bondade automática da globalização regulada pela economia, segundo a qual fez crescer o Brics. Francisco não dissente de todo o neoliberalismo, mas daquele radical, pois o desenvolvimento não é só econômico e de qualquer maneira, ainda que seja à custa da justiça, sem respeitar os direitos dos trabalhadores, e sem promover o progresso social. Se a globalização da economia produziu riqueza e crescimento econômico para alguns, é necessário questionar se isso veio segundo a justiça e não a custo da desigualdade. O bem comum deve estruturar toda a política econômica, constituir programa (EG. 203).

Para realizar o bem comum mundial é necessário mercados financeiros e monetários livres, estáveis, transparentes, democráticos, éticos, funcionais aos trabalhadores, às impressas, às famílias e às comunidades locais, como foi dito na encíclica Laudato Si. Francisco critica claramente a economia que promove a cultura do descartável e que produz sujeitos-

\footnotetext{
${ }^{5}$ Ver https://www.imf.org/external/pubs/ft/weo/2018/01/weodata/index.aspx

${ }^{6}$ Ver http://hdr.undp.org/en/2018-update
} 
rejeito, e não as teorias econômicas do liberalismo. Este pode ser um sistema aceitável para o crescimento de um país, na medida que integre em si um humanismo ético.

O pensamento de Francisco está claramente fundado nas informações que foram oferecidas precedentemente. Basta observar os dados da ODCE no crescimento de políticas de equilíbrio não fratricidas nos países de economia liberal. Ademais, ao lancar um olhar a geopolítica regional, pode-se perceber que o que define o desenvolvimento humano não é o sistema econômico, mas a postura ética na economia que assume a sociedade civil e o Estado constitucional. Nesse sentido, uma Cuba ou Chile, de regimes políticos econômicos tão diversos, superam um Brasil em desenvolvimento humano, ainda que este último ostente a poderosa posição de $9^{\mathrm{a}}$. economia mais rica do mundo.

Francisco ensina que, num contexto, em que as riquezas das nações são criadas pela especulação e não pelo empreendimento e trabalho, o único que importa são as variações que determinam os mercados, e constroem e descontroem os mecanismos financeiros. Esta concepção neoliberal mortifica a dignidade de muitos. Trata-se, portanto, de entender as causas estruturais da pobreza e da iniquidade $(E G, \mathrm{n} .202)$ e superar o assistencialismo. O Pontífice aponta para a criação de uma economia inclusiva com ajuda da política comprometida com a equidade, e com um Estado constitucional fazendo valer os direitos dos cidadãos inscritos pelo consenso da maioria.

Urge uma política que não sucumba ao capitalismo especulativo descontrolado, mas ponha a frente o serviço comum ( $E G$ n. 205). É necessário pessoas politicamente empenhadas para sanar as raízes profundas dos males sociais e que supere a dicotomia maniqueísta entre economia e bem comum social.

\section{Considerações Finais}

Diante do exposto, percebe-se que Francisco move seu discurso para o que se chama de novo pacto social sobre a economia. O evento organizado para Assis em 2020, intitulado Economy of Francesco, é um argumento de atualidade e testemunho, clara voz profética sobre as distorções do capitalismo laissez-faire. O discurso, entretanto, não está fundado no modelo anti-modernista do início do século XX. Ao contrário, Francisco corrobora com perspectivas do capitalismo, contudo, propõe uma alternativa antropológica ao modelo imperante do Ocidente.

Destarte, o pensamento de Adam Smith, ao navegar pela mesma escola tomasiana, pensa a propriedade em razão de sua melhor administração e eficiência. Assim como Tomás, a Tradição do magistério eclesial e, consequentemente, Francisco, e a moral smithiana, o capitalismo é um instrumento válido, e pode-se dizer em razão de sua história, real fator social para a riqueza dos povos.

O que não converge na perspectiva tomasiana e do pontífice é o uso dos bens. Para Francisco, os bens tem uma lógica de uso comunitário, dever também está a serviço daqueles que mais necessitam, e sobretudo, são relacionais e não apenas individuais. Na perspectiva smithiana, o capitalismo ainda dialoga com os conceitos de simpatia-empatia, na construção de uma moral do dever ser. Contudo, as versões neoclássicas e neoliberais trataram de expurgar todo resquício de moral da alteridade do capitalismo e a única logica é aquela do mercado, da especulação e do individualismo.

Nos temos desse capitalismo ultraliberal que encontra seu modus operandi no início deste século, o diálogo com Francisco torna-se conflitante. Contudo, outro capitalismo é possível, e exatamente nesse caminho, o Pontífice tem construído esse novo pacto social por um capitalismo mais humano, fundado nos conceitos do multiculturalismo, multireligiosidade, ecologia, e ademais, nos ganhos do Estado democrático de direitos e no constitucionalismo garantistas dos direitos socais do século XXI.

\section{Referências}

Aquino, T. de. (2001). Suma Teológica. Edições Loyola. 
Bento XVI. Carta Encíclica Caritas in Veritate. www.vatican.va. .

Bercovici, G. (2006). O estado de exceção econômico e a periferia do capitalismo. Pensar, 11, 95-99.

Bercovici, G. (2011). Politica economica e direito economico. Fac. Dir. Univ. SP105, 389-406

Carducci, M. (2014). Il quadrilatero dello sveluppo e i postulati perniciosi per il futuro del constitucionalismo, em Pompeu, G.;

CARDUCI, M.; SANCHEZ, M. Direito Constitucional nas relações econômicas: entre o crescimento econômico e o desenvolvimento humano. Lumen Juris, $.177-202$.

Chang, Ha-Joon. (2002). Kicking Away the Ladder: Development Strategy in Historical Perspective. Anthem Press.

Clark, C. (2017). Economy of exclusion: global perspective on Pope Francis on Capitalism. Journal of Vicentian Social Action, 2, 4-11,

Edgeworth, F. Y. (1881). Mathematical psychics. An assey on the application of mathematics to the moral sciences. C. Kegan Paul \& Co.

Francisco. Carta Encíclica Laudato si. www.vatican.va.

Francisco. Discorso ai participante all incontro mundiale dei movimenti popolari www.vatican.va.

Francisco. Exortação apostólica Evangelii Gaudium. www.vatican.va.

Francisco. Exortação Apostólica Evangelii Gaudium. www.vatican.va.

Fukuyama, F. (1992). O fim da História e o último homem. Rocco, 1992.

Heilbroner, R. L. (1985). The nature and logic of capitalism. Norton.

Hobbes, L., \& Zarka, Y. C. (1992). La propriété chez Hobbes. Archives de philosophie, 55 (4)

Humphrys, J. Capitalism: the problem or the solution. yougov.co.uk.

Kerstenetzky, C. L., \& Guedes, P. G. (2018). O welfare state resiste? Desenvolvimentos recentes do estado social nos países da OCDE. Ciência \& Saúde Coletiva, 23,2096-2106.

Leão XIII. Carta encíclica Rerum Novarum. 1891. www.vatican.va.

Lock, J. Second Treatise on Government. earlymoderntexts.com.

Nunes, J. A. (2011). Avelãs. As duas ultimas caras do Estado capitalista. Pensar, 16, 409-472

Nussbaum, M. (2015). Sem fins lucrativos: porque a democracia precisa das humanidades. Martins Fontes, p. 15.

Marx, K. (1998). A ideologia alemã. (2a. ed.), Martins Fontes.

Mccloskey, D. N. (2018).The great enrichment came and comes from ethics, in Melzer, Arthur M., \& Kautz, Steven J. (Org). Are Markets moral? Philadelphia: UP Press, pp. 136-166.

Mises, L. V. (1987). Liberalismo segundo a tradição clássica. José Olympio Editora/Instituto Liberal.

Pio XI. Carta Encíclica Quadragésimo Anno. www.vatican.va.

Polanyi, K. (1957). The great transformation. Boston: Beacon Press

Pompeu, G., \& Natercia, S. Liberdade e igualdade: condicionamentos democráticos para o desenvolvimento humano, para o crescimento econômico e à estabilidade social, em Pompeu, G., Carduci, M., \& Sanchez, M. (2014). Direito Constitucional nas relações econômicas: entre o crescimento econômico e o desenvolvimento humano. Lumen Juris.

Santo Agostinho. (2016). As Confissões. Col. Patrística. (7a. ed.), Paulus.

Sen, A. (2008). Desigualdade reexaminada. (2a. ed.), Record, p. 37.

Shiller, R. J. (2012). Finanza e società giusta. Il Mulino.

Smith, A. (2007). A riqueza das nações. Zahar, .2007.

Smith. A. (2015). A teoria dos Sentimentos morais. (2a. ed.), Martins Fontes.

Stark, W. (2014). America, Ideal and reality. Routledge.

Telly, C. (2013). The classical economic model and the nature of property in the eighteenth and nineteenth centuries. Tulsa Law Review, $13,406-507$.

Tornielli, G. (2015). Papa Francesco. Questa economia uccide. Con un 'intervista esclusiva su capitalismo e giustizia sociale. Piemme: Milano.

Yunus, M. (2008). Um mundo sem pobreza. Empresa social e o futuro do capitalismo. Ática. 